\title{
Determination of Iron Content in Iron Ore by Fluorescent X-Ray Spectroscopy-Effects of Cobalt Internal Standard in Binder-Briquetted Specimens*
}

\author{
By Kazuo Kawamura**, Toshio Watanabe***, Kôichi Nishizaka***, \\ Masaaki Onodera and Takeshi Uemura****
}

\begin{abstract}
Based on Claisse's model and considering the effects of the particle size and mixing rate, a theoretical formula expressing the intensity of the fluorescent X-rays emitted from heterogeneous systems has been established, by which the degree of homogeneity can be determined. The formula indicates that the effect of cobalt on the internal standard analysis of Fe content increases when the specimen and the element added thereto are pulverized to $2-3 \mu \mathrm{m}$ or finer and thoroughly mixed. Insufficient mixing results in an apparent increase in the particle size. As microscopically confirmed, an iron ore sample, added with a briquetting binder and an internal standard, can be pulverized to $5 \mu \mathrm{m}$ or finer by wet crushing for 3-5 min. This crushing also assures good mixing. This method almost fully cancels the influence of the matrix, and permits accurate determination of Fe content in various grades of iron and manganese ores and slags. The calibration curve is not necessarily linear over the wide Fe content range, probably because of the slight difference between the absorption coefficients of $\mathrm{Fe}$ and $\mathrm{Co}$.
\end{abstract}

(Received February 8, 1980)

\section{Introduction}

Well-known eq. (1) formulating the intensity of fluorescent X-rays is applicable only to such specimens whose surface is radiographically smooth and components are uniformly distributed. Specimens satisfying these requirements are called homogeneous specimens and permit compensation of the influences of coexisting elements, such as absorption and exciting effects of $\mathrm{X}$-rays.

$$
I_{A}=K_{\mathrm{A}} \cdot W_{A} / \mu_{A}
$$

where

$I_{A}=$ intensity of the desired line spectrum

$K_{A}=$ excitation constant

$W_{A}=$ concentration of the desired element in specimen

* This paper originally published in Japanese in J. Japan Inst. Metals, 33 (1969), 679.

** Nippon Steel Co., Ltd., Process Technology R \& D Laboratories, Kitakyushu-shi 805, Japan.

*** Nippon Steel Co., Ltd., Products R \& D Laboratories, Sagamihara shi 229, Japan.

**** Nippon Steel Co., Ltd., Hirohata Works, Himeji shi 671-11, Japan.
$\mu_{A}=$ mass absorption coefficient of specimen for the desired line spectrum

Most of all the analyzable elements in steel are thought as being the elements in homogeneous specimens. Sugimoto ${ }^{(1)}$, Adachi $^{(2)}$, Hirokawa $^{(3)}$, Marti ${ }^{(4)}$ and Beattie ${ }^{(5)}$ derived equations for correction and individually produced satisfactory calibrating results with actual specimens. Fluorescent X-ray spectroscopy is also applied to the analysis of heterogeneous specimens; for example, those which are compositionally homogeneous but whose surfaces are not smooth (e.g., briquetted steel chip specimens), those which are not bulky but pulverulent, and those which vary in chemical composition from particle to particle. These specimens, to which the application of eq. (1) is complicated, are termed heterogeneous specimens here. Compared with the homogeneous specimens, the heterogeneous specimens emit fluorescent $\mathrm{X}$-rays of such intensities that result in lower measuring accuracy. The authors studied the method of preparing such heterogeneous specimens that resemble homogeneous ones to the greatest possible extent. The causes of differences in the fluorescent X-ray intensity between the hetero-

1980 Vol. 21 
geneous and homogeneous specimens, together with their correcting methods, were also studied. These studies on the intensity of fluorescent X-rays emitted from the heterogeneous specimens expand the applicable range of fluorescent X-ray spectroscopy. Determination of causes of analytical errors leads to a decrease in the errors and, hence an increase in analyzing accuracy. With the fluorescent $X$-ray spectroscopy being increasingly automated, it seems essential to analyze and digitialize such errors with the homogeneous specimens. This paper deals with pulverulent specimens, typifying the heterogeneous specimens, and particularly with the influence of the size and mixing ratio of powder particles, which are thought to be most important, on the effect of the internal standard.

\section{Theoretical Equation Formulating the Fluorescent X-ray Intensity from Pulverulent Specimens}

A heterogeneous specimen consists of a mixture of particles emitting the desired fluorescent $\mathrm{X}$-ray and non-emitting particles. Claisse's mosaic specimen mixing model ${ }^{(6)}$ gives an

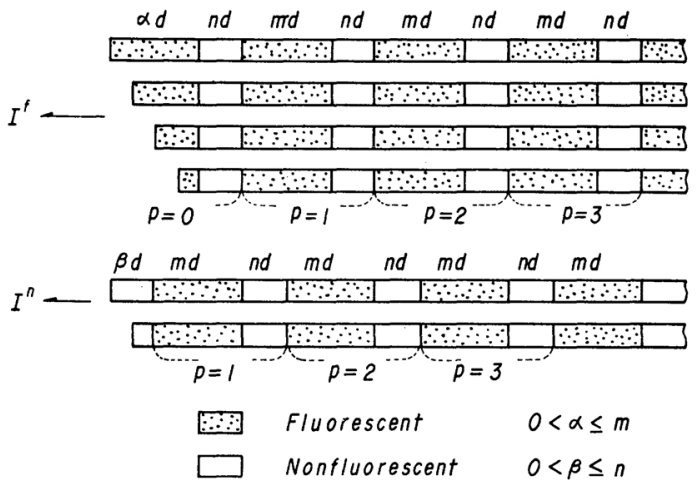

Fig. 1 Idealized model of mixed sample for inhomogeneous system, based on Claisse's. The left side represents the sample surface.

equation for the intensity of fluorescent X-rays emitted from the heterogeneous specimens. The model shown in Fig. 1 was derived from this mosaic model, with consideration given to cases in which mixing does not proceed perfectly.

This model on the average contains $m$ pieces of fluorescent X-ray emitting particles (with a diameter $d$ ). (The value of $n$ depends on the mixing ratio by volume and the value of $m$.) The intensity of the fluorescent X-rays emitted from this model is expressed as follows:

$$
\begin{aligned}
& I=\left(\sum_{\alpha=1}^{m} I^{f}+\sum_{\beta=1}^{n} I^{n}\right) /(m+n)=\frac{Q_{f} \rho_{f} C_{f} I_{0}}{a_{f}} \frac{m}{m+n}\left[1+\frac{1}{m} \frac{e^{-a_{n} d}-e^{-a_{f} d}}{\left(1-e^{-a_{f} d}\right)\left(1-e^{-a_{n} d}\right)} \frac{\left(1-e^{-m a_{f} d}\right)\left(1-e^{-n a_{n} d}\right)}{1-e^{-\left(m a_{f}+n a_{n}\right) d}}\right] \\
& I^{f}=\frac{Q_{f} \rho_{f} C_{f} I_{0}}{a_{f}}\left[1-e^{-\alpha a_{f} d}\left(1-e^{-n a_{n} d}\left(1-e^{-m a_{f} d}\right)\left\{\sum_{p=1}^{\infty} e^{-(p-1)\left(m a_{f}+n a_{n}\right) d}\right\}\right)\right] \\
& I^{n}=\frac{Q_{f} \rho_{f} C_{f} I_{0}}{a_{f}} e^{-\beta a_{n} d}\left(1-e^{m a_{f} d}\right)\left\{\sum_{p=1}^{\infty} e^{-(p-1)\left(m a_{f}+n a_{n}\right) d}\right\} .
\end{aligned}
$$

In eq. (2): $I^{f}=$ intensity of the desired line spectrum from a unit surface area of a specimen having particles emitting the desired fluorescent X-ray at the surface; $I^{n}=$ intensity of the desired line spectrum from a unit surface area of a specimen having particles not emitting the desired fluorescent $\mathrm{X}$-rays at the surface; $Q_{f}=$ excitation constant for the desired element; $\rho_{f}=$ density of particles emitting the desired fluorescent X-rays; $C_{f}=$ content of the desired element in particles emitting the desired fluorescent X-rays; $I_{0}=$ primary X-ray intensity; $a_{f}=$ linear absorption coefficient for the desired line spectrum in relation to particles emitting the desired fluorescent X-rays; $a_{n}=$ absorption coefficient for the desired line spectrum in relation to particles not emitting the desired fluorescent $X$-rays; $I=$ total intensity of the desired line spectrum emitted from the specimen; and suffix $n$ designates particles not emitting the desired fluoresecent $\mathrm{X}$-rays. $p$ is a serial number for each pair of a particle 
emitting the desired fluorescent X-rays (having an apparent diameter $m d$ ) and a particle not emitting the desired fluorescent X-ray (having an apparent diameter $n d$ ), counted from the specimen surface as shown in Fig. 1.

By reducing the particle diameter $d$, eq. (2) can be approximated to eq. (3) independent of the particle diameter $d$ (approximation: $\exp (-x) \fallingdotseq 1-x)$.

$$
\underset{d \rightarrow 0}{I=} Q_{f} I_{0} C_{f} \frac{W_{f}}{\mu_{f} W_{f}+\mu_{n}\left(1-W_{f}\right)} .
$$

In eq. (3): $W_{f}=$ mixing ratio by weight of paticles emitting the desired fluorescent X-rays; $\mu_{f}=$ mass absorption coefficient for the desired line spectrum in relation to particles emitting the desired fluorescent X-rays; and $\mu_{n}=$ mass absorption coefficient for the desired line spectrum in relation to particles not emitting the desired fluorescent X-rays.

The degree of homogeneity $\psi$ is defined by the following equation:

$$
\varphi=\frac{I(d)-I(\infty)}{I(0)-I(\infty)} .
$$

In eq. (4): $I(0)=$ intensity of fluorescent $\mathrm{X}$-rays when particle diameter is infinitely reduced (to a perfectly homogeneous state); $I(\infty)=$ intensity of fluorescent X-rays when particle diameter is infinitely increased (to a perfectly heterogeneous state); and $d=$ particle diameter.

From eqs. (2) and (4), $\psi$ is expressed as

$$
\begin{aligned}
\varphi= & \frac{m a_{f}+n a_{n}}{m n\left(a_{f}-a_{n}\right)} \frac{e^{-a_{n} d}-e^{-a_{f} d}}{\left(1-e^{-a_{f} d}\right)\left(1-e^{-a_{n} d}\right)} \\
& \times \frac{\left(1-e^{-m a_{f} d}\right)\left(1-e^{-n a_{n} d}\right)}{1-e^{-\left(m a_{f}+n a_{n}\right) d}} .
\end{aligned}
$$

Table 1 shows the values calculated from eq. (5).

As seen from Table 1, no specimens can be regarded as radiographically homogeneous unless the particle size is held below 2 to $3 \mu \mathrm{m}$ after being mixed. The calculation results in Table 1 are for $m=1$ (i.e., a model having one fluorescent X-ray emitting particle). When $m=$ 2 , the particle diameter should be reduced counterbalancingly. Namely, the advantage of pulverization is offset unless the components are

\begin{tabular}{|c|c|c|c|c|c|c|}
\hline \multicolumn{2}{|c|}{ System } & \multirow{2}{*}{$\begin{array}{l}W_{f} \\
(\%)\end{array}$} & \multicolumn{4}{|c|}{ Calculated $\varphi(m=1)$} \\
\hline Fluo. & Non-F. & & $\begin{array}{l}d=1 \\
\mu \mathrm{m}\end{array}$ & $\stackrel{5}{\mu \mathrm{m}}$ & $\begin{array}{l}10 \\
\mu \mathrm{m}\end{array}$ & $\begin{array}{l}50 \\
\mu \mathrm{m}\end{array}$ \\
\hline \multirow{3}{*}{$\mathrm{Fe}_{2} \mathrm{O}_{3}$} & $\mathrm{SiO}_{2}$ & $\begin{array}{l}57.7 \\
19.2\end{array}$ & $\begin{array}{l}1.00 \\
0.98\end{array}$ & $\begin{array}{l}0.96 \\
0.86\end{array}$ & $\begin{array}{l}0.88 \\
0.63\end{array}$ & $\begin{array}{l}0.26 \\
0.08\end{array}$ \\
\hline & $\mathrm{CaO}$ & $\begin{array}{l}57.7 \\
19.2\end{array}$ & $\begin{array}{l}1.00 \\
0.99\end{array}$ & $\begin{array}{l}0.93 \\
0.75\end{array}$ & $\begin{array}{l}0.77 \\
0.46\end{array}$ & $\begin{array}{l}0.09 \\
0.02\end{array}$ \\
\hline & $\mathrm{Al}_{2} \mathrm{O}_{3}$ & $\begin{array}{l}57.7 \\
19.2\end{array}$ & $\begin{array}{l}1.00 \\
1.00\end{array}$ & $\begin{array}{l}0.96 \\
0.88\end{array}$ & $\begin{array}{l}0.88 \\
0.65\end{array}$ & $\begin{array}{l}0.25 \\
0.07\end{array}$ \\
\hline
\end{tabular}

Table 1 Degree of homogeneity for mixed specimens of varying particle sizes. ( $\psi$ values for FeK from iron and other oxides plus stearic acid systems)

mixed to the greatest possible extent. As the degree of homogeneity $\psi$ changes with varying specimen composition, each specimen should be pulverized well, when analyzing specimens having different matrices, so that the degree of homogeneity is kept on the safe side. In the calculation of Table 1 , the $\mathrm{K}$ absorption edge of iron is used as the wavelength of the primary $\mathrm{X}$-rays.

\section{Experimental Results}

\section{Analytical problems in the preparation of pulverulent specimens}

Pulverulent specimens are used mainly for the analysis of glass, cement, ores and slag, though not altogether free from errors associated with their condition. According to a broad classification, such errors result from heterogeneity due to inappropriate particle diameter and particle-size distribution, mineral structures in particles, particle-to-particle composition variation, mixing with a diluent and/ or binder, and inappropriate packing of pulverulent materials. Affecting the homogeneity of the specimen, all these factors should be considered in formulating an equation for the intensity of fluorescent X-rays. Homogenizing is one of the effective means for decreasing such errors. Pulverization of materials is a shortcut for preparing a homogeneous, briquetted specimen. How to realize easy, quick pulverization has been an important problem. Binderbriquetted specimens are not homogenious in quality because iron ore powders are not 
uniform in chemical compositions and because a test portion of iron ore is mixed with a binder of a completly different chemical composition. Therefore, it is anticipated to establish a new sample preparation technique which provides us with a completely homogeneous test specimen. With such materials as iron ore whose mineral structure varies from brand to brand, the conventional dry crushing method has posed difficulties in mixing and pulverization. Such difficulties have led to considerable measurement variations and errors. With dry-crushed iron ores, analytical errors amount to several percent in terms of iron content, which have been unanalyzable and uncorrectable as the matrix effect (absorption coefficient). These extensive errors are due to the influence of mineral structures in iron ore and unpulverized specimens. Figure 2 shows the results obtained from a fusion method using anhydrous borax.

This is a method of internal standard spectroscopy in which cobalt oxide is added to the specimen to be analysed. By taking the ratio of the spectral line intensities of iron to cobalt, this method permits compensations for the influence of the particle size and mixing ratio as well as matrix effects. Dilution and fusion help reduce matrix effects and eliminate the

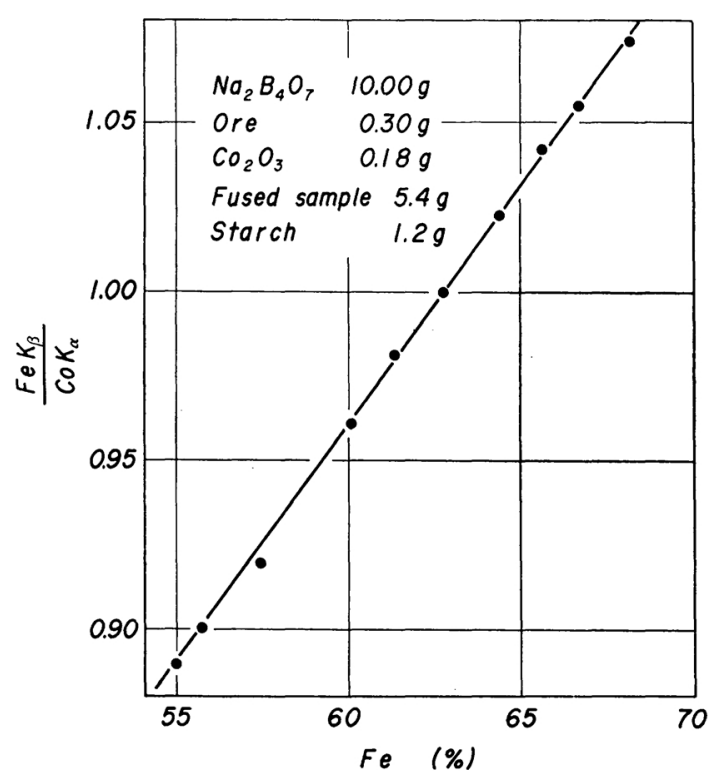

Fig. 2 Results of the fusion method for iron ores. influence of mineral structures. Corrected determination of $\mathrm{Fe}$ was done with a standard deviation of $0.11 \%$.

Involving intricate procedures, however, the fusion method is unsuitable for rapid fluorescent X-ray spectroscopy. The briquetted specimens are convenient for use if pulverized materials are available. The conventional dry crushing method does not achieve sufficient homogenization of specimens, with pulverization and mixing not proceeding, despite a prolonged crushing time. Wet crushing ${ }^{(7)}$ has greatly improved pulverization and mixing. Figure 3 shows an example of specimen preparation by the wet crushing method.

The quantity of $n$-hexane, added to assist pulverization and mixing, was determined so that particles of different specific gravities should not separate after crushing. On completion of crushing, $n$-hexane was immediately vaporized with a drier. Powdered stearic-maleic acid polymer (abbreviated SM-P) was used as a binder. Starch and stearic acid also showed good results as a binder. The wet-crushed specimen does not stick fast to the crushing vessel, which can therefore be rinsed clean, instantly ready for the next crushing operation. Sticking fast to the vessel, the dry-crushed specimen sometimes calls for the help of sandpaper.

\section{Effects of internal standard on heterogeneous specimens}

Specimens added with cobalt oxide and fused with anhydrous borax consist of homogeneous particles. The intensity of iron and cobalt spectra emitted from an iron-containing specimen of this type are similarly affected by mixing (with a binder). Because the iron-cobalt

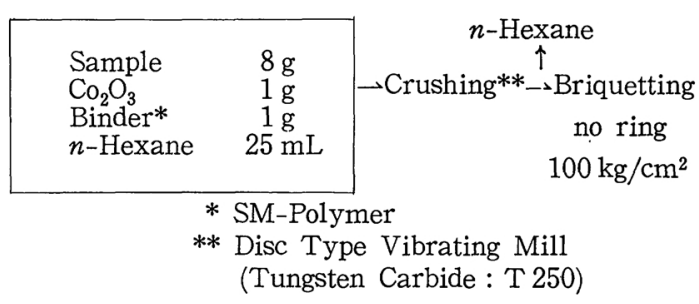

Fig. 3 A diagram for the sample preparation by wet crushing. 
spectrum, intensity ratio thus remains unchanged, the cobalt internal standard works with this specimen. The crushed-and-mixed specimens differ from the fused ones, emitting iron and cobalt spectra from different particles. But, if crushed and mixed well, they become comparable to the fused specimens, though not exactly. That is, even a crushed-and-mixed specimen permits the internal standard to work, if it is radiographically homogeneous. As mentioned in Chapter II, a specimen is regarded as being radiographically homogeneous if its particles are 2 to $3 \mu \mathrm{m}$ or finer and mixed well.

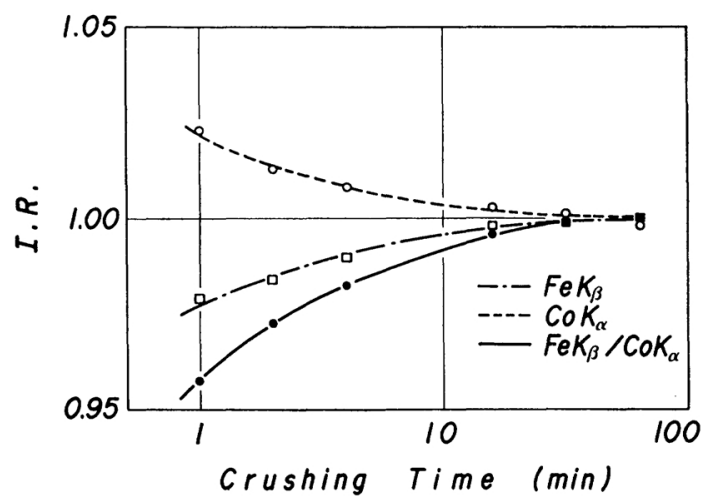

Fig. 4 Relative intensities of $\mathrm{FeK} \beta$ and $\operatorname{CoK} \alpha$ vs crushing time for Brazilian ore.

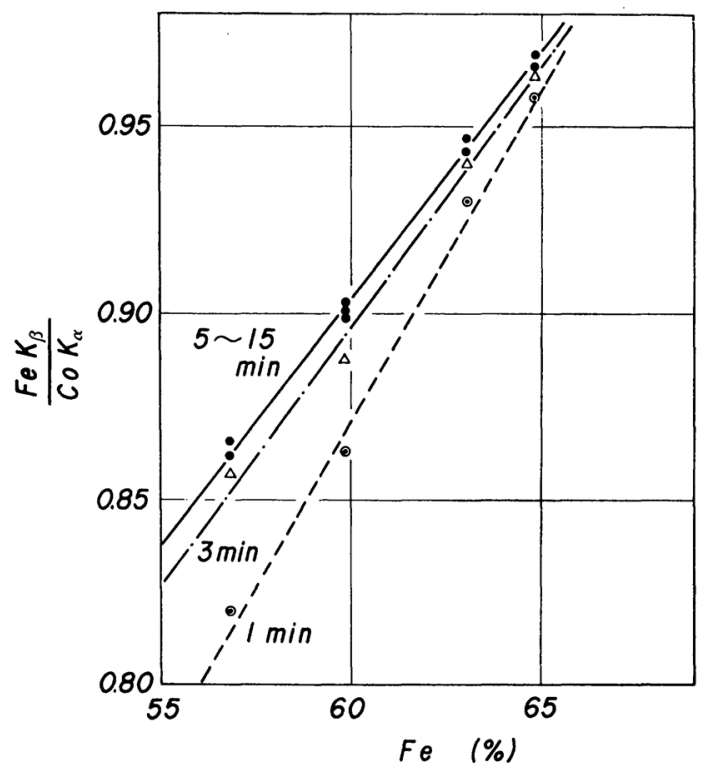

Fig. 5 Calibration curve vs crushing time for iron ores (Binder: stearic acid).
The effect of the internal standard on a specimen prepared by wet crushing was studied. The cobalt oxide, added as an internal standard, was a fairly well pulverized reagent. Brazilian iron ore under 150-mesh was wet-crushed (see Fig. 3), and changes in the iron and cobalt spectra with the crushing time were observed as shown in Fig. 4.

The intensity of $\operatorname{CoK} \alpha$ spectrum dropped with increasing crushing time, which was due to the increased absorption of iron by the increasingly homogenized, mixed specimen. Figure 5 shows the change in the calibration curve, for a specimen bound with stearic acid, with the crushing time. As seen, the calibration curve substantially stabilized after 5-min crushing.

(1) Effects of coblat internal standard when particles emitting desired fluorescent X-ray have different chemical compositions

To $10 \mathrm{~g}$ each of ferro-manganese, -phosphrous, -niobium, -silicon, -titanium, -chromium, -vanadium and -silicon calcium, iron oxide, Mohr's salt, red and yellow prussiates was added $1 \mathrm{~g}$ of cobalt oxide and $2 \mathrm{~g}$ of stearic acid. The mixture was crushed in $n$-hexane for $10 \mathrm{~min}$ and briquetted. The $\mathrm{FeK} \alpha$, $\mathrm{FeK} \beta$ spectra intensities of each briquetted specimen were measured as shown in Fig. 6.

Evidently, $\mathrm{FeK} \alpha$ in ferro-manganese was overlapped with the $\mathrm{MnK} \beta$ spectrum. In other specimens, the internal standard well offset matrix effects.

(2) Effects of cobalt internal standard when particles not emitting desired fluorescent X-ray have different chemical compositions

Table 2 shows combinations of fluorescent $\mathrm{Fe}_{2} \mathrm{O}_{3}$ with various non-fluorescent components.

The variation in the $\operatorname{CoK} \alpha$ and $\mathrm{FeK} \alpha$ spectrum intensities indicates the existence of variations in $\mathrm{X}$-ray absorption rates among the individual specimens. With the cobalt internal standard, however, the specimens exhibited good results, except for the specimen containing manganese dioxide which was 


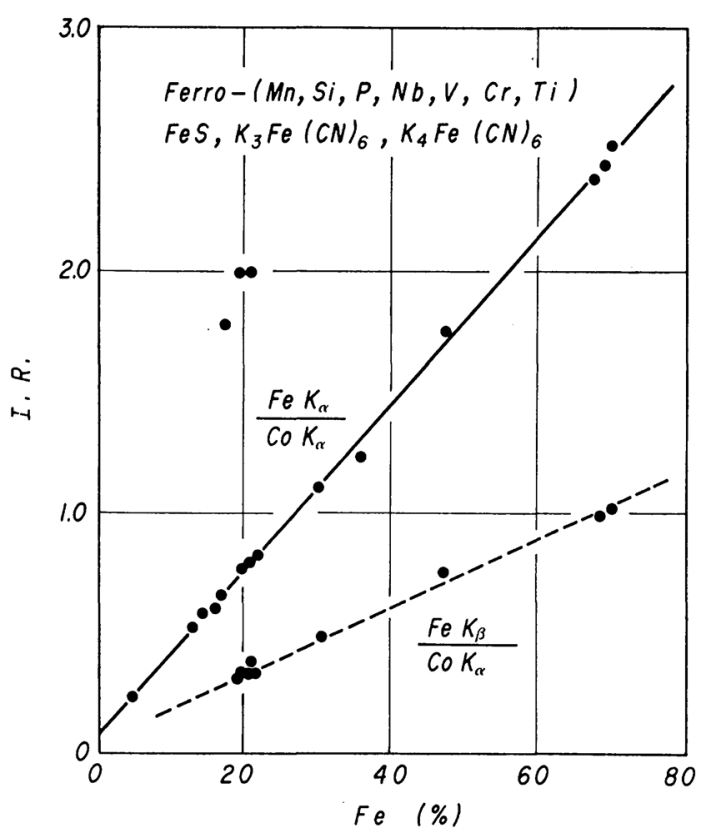

Fig. 6 Intensity-ratios iron/cobalt vs iron contents in various specimens.

Table 2 Effects of internal standard (Co) on $\mathrm{Fe}$ in mixed specimens containing different nonfluorescent particles.

\begin{tabular}{cllll}
\hline $\begin{array}{c}\text { Fluo. part. } \\
8 \mathrm{~g}\end{array}$ & $\begin{array}{c}\text { Non-fluo. } \\
2 \mathrm{~g}\end{array}$ & $\mathrm{FeK} \alpha$ & $\mathrm{CoK} \alpha$ & $\begin{array}{c}\text { FeK } \alpha \\
\mathrm{CoK} \alpha\end{array}$ \\
\hline & $\mathrm{SiO}_{2}$ & $0.84_{8}$ & $1.04_{8}$ & 0.81 \\
& $\mathrm{Al}_{2} \mathrm{O}_{3}$ & $0.85_{9}$ & $1.02_{8}$ & 0.84 \\
& $\mathrm{~S}$ & $0.71_{4}$ & $0.88_{9}$ & 0.80 \\
& $\left.\mathrm{NH}_{4}\right)_{3} \mathrm{PO}_{4}$ & $0.87_{6}$ & $1.11_{1}$ & 0.79 \\
& $\mathrm{CuSO}_{4}$ & $0.86_{8}$ & $1.07_{1}$ & 0.81 \\
& $\mathrm{CaCO}_{3}$ & $0.66_{5}$ & $0.83_{4}$ & 0.80 \\
& $\mathrm{TiO}_{2}$ & $0.67_{3}$ & $0.82_{0}$ & 0.82 \\
$\mathrm{Fe}_{2} \mathrm{O}_{3}$ & $\mathrm{ZnO}$ & $0.83_{2}$ & $1.02_{8}$ & 0.81 \\
& $\mathrm{PbO}$ & $0.56_{3}$ & $0.69_{6}$ & 0.81 \\
& $\mathrm{~V}_{2} \mathrm{O}_{5}$ & $0.66_{8}$ & $0.82_{5}$ & 0.81 \\
& $\mathrm{~K}_{2} \mathrm{CrO}_{4}$ & $0.65_{6}$ & $0.81_{1}$ & 0.81 \\
& $\mathrm{NaBiO}_{4}$ & $0.61_{7}$ & $0.76_{7}$ & 0.80 \\
& $\mathrm{MgO}$ & $0.88_{1}$ & $1.08_{8}$ & 0.81 \\
& $\mathrm{NiSO}_{4}$ & $0.88_{0}$ & $1.08_{1}$ & 0.81 \\
& $\mathrm{MnO}_{2}$ & $0.84_{6}$ & $0.77_{0}$ & 1.09 \\
\hline \hline
\end{tabular}

affected by the spectral overlap mentioned in Section (1).

(3) Effects of cobalt internal standard on commercial samples

Effects of the cobalt internal standard were studied, using iron ore samples according to

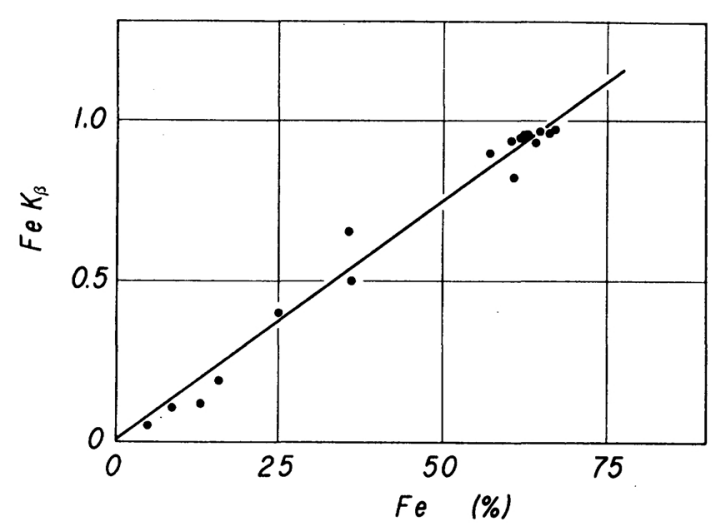

Fig. 7 Intensity of $\mathrm{FeK} \beta$ vs iron content for various standard samples (obtained by wet crushing).

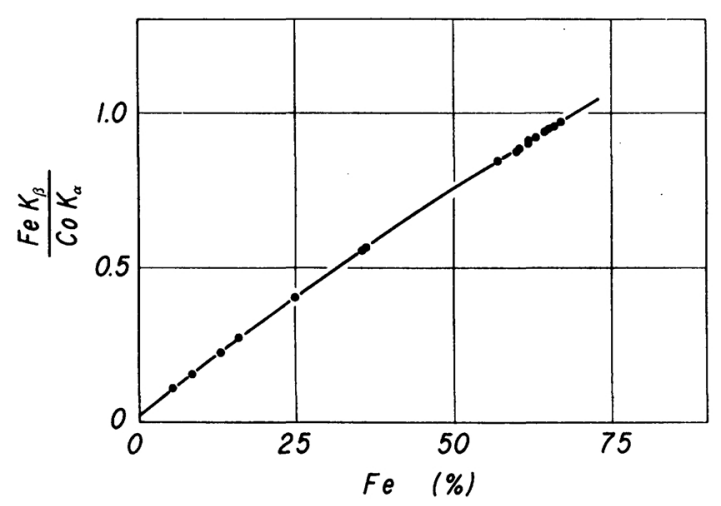

Fig. 8 Results of the internal standard method for various samples.

the standards of the Iron \& Steel Institute of Japan $^{(8)}$, British Chemical ${ }^{(9)}$ and Nippon Steel Corporation. Figure 7 shows the relationship between the intensity of $\mathrm{FeK} \beta$ spectrum and iron content. Figure 8 and Table 3 show the results obtained from the use of the cobalt internal standard. As seen, favorable effects resulted over a wide $\mathrm{Fe}$ content range, though no linear regression equation was formulated. The fluorescent X-ray analytical values in Table 3 were derived from eq. (6) established by applying the least squares method to the entire Fe content range.

$$
\begin{aligned}
\mathrm{Fe} \%= & 0.114_{9}\left(\frac{\mathrm{FeK} \beta}{\operatorname{CoK} \alpha}\right)^{2} \\
& +0.588_{7}\left(\frac{\mathrm{FeK} \beta}{\operatorname{CoK} \alpha}\right)-0.010 .
\end{aligned}
$$


Table 3 Analytical results concerning effects of internal standard.

\begin{tabular}{lllrr}
\hline $\begin{array}{c}\text { Sample } \\
\text { No. }\end{array}$ & CoK $\alpha$ & $\begin{array}{l}\text { Chem. } \\
\text { Fe } \%\end{array}$ & $\begin{array}{l}\text { X-ray } \\
\text { Fe } \%\end{array}$ & \multicolumn{1}{c}{ X-C } \\
\hline 800 & $1.03_{9}$ & 62.97 & 62.87 & -0.10 \\
801 & $1.02_{3}$ & 64.63 & 64.96 & 0.33 \\
810 & $0.97_{8}$ & 64.86 & 65.37 & 0.51 \\
811 & $1.05_{1}$ & 61.84 & 61.44 & -0.40 \\
830 & $0.92_{9}$ & 60.54 & 60.17 & -0.37 \\
850 & $1.00_{3}$ & 66.83 & 66.99 & 0.16 \\
F-1 & $1.06_{7}$ & 60.10 & 59.46 & -0.64 \\
F-2 & $1.06_{1}$ & 56.95 & 57.09 & 0.14 \\
21 & $1.04_{2}$ & 61.81 & 62.39 & 0.51 \\
$22-\mathrm{a}$ & $0.54_{5}$ & 12.99 & 12.75 & -0.24 \\
$174 / 1$ & $0.70_{0}$ & 8.47 & 8.34 & -0.13 \\
$174 / 2$ & $0.71_{7}$ & $15.9 \sim$ & 15.92 & 0.02 \\
$175 / 1$ & $1.00_{7}$ & 66.15 & 65.69 & -0.46 \\
$176 / 1$ & $0.47_{7}$ & $5.2 \sim$ & 5.42 & 0.22 \\
301 & $0.98_{8}$ & 24.75 & 24.92 & 0.17 \\
302 & $1.16_{7}$ & 35.50 & 35.64 & 0.14 \\
303 & $0.88_{5}$ & 35.95 & 36.14 & 0.19 \\
\hline \hline
\end{tabular}

$\sigma: 0.34$

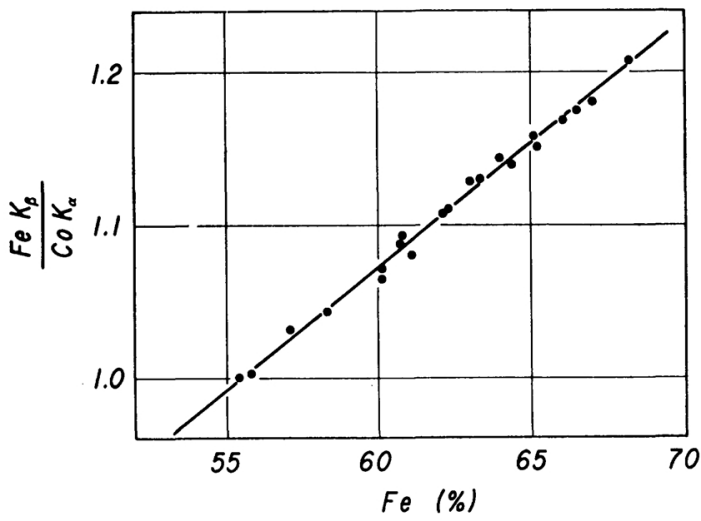

Fig. 9 Calibration curve for iron ores.

Figure 9 shows the results of linear regression applied to the 21 iron ore samples according to Nippon Steel standards. Benefiting from the effect of the internal standard, the analytical error was $0.32 \mathrm{Fe} \%(0.5 \mathrm{CV} \%)$ in terms of the standard deviation.

The quantity of each sample pulverized for the experiment was only $10 \mathrm{~g}$. With this limited specimen quantity, weighing and other handling were expected to involve considerable errors. Therefore, errors due to such specimen preparation procedure were determined, using 11 separate specimens (crushed for 10 minutes) of Brazilian iron ore. The errors determined averaged $0.20 \mathrm{Fe} \%$, with an analytical error of $0.11 \mathrm{Fe} \%$, both in terms of the standard deviation.

\section{Discussion}

Briquette specimens were prepared by pressforming wet-crushed Brazilian iron ore (Fig. 3), using SM-P dissolved in acetone as a binder. The specimens were subjected to centrifugation at $2000 \mathrm{rpm}$. As microscopically determined, their pulverized product, after 3-5 min crushing, consisted of particles not exceeding $5 \mu \mathrm{m}$ in diameter. With this particle size, the homogeneity $\psi$ of the specimens, discussed in Chapter II, proved to be high enough to benefit from the effect of the internal standard. Good results were obtained with commercial samples, though no linear regression equation was formulated over a wide $\mathrm{Fe}$ content range. The cause of this nonlinearity was studied. When cobalt is added to eq. (3), the intensities of iron and cobalt spectra are expressed by eq. (7) and (8), and their ratio by eq. (9).

$$
\begin{aligned}
& I_{\mathrm{Fe}}=K_{\mathrm{Fe}} C_{\mathrm{Fe}} \frac{W_{\mathrm{Fe}}}{\mu_{\mathrm{Fe}} W_{\mathrm{Fe}}+\mu_{\mathrm{Co}} W_{\mathrm{Co}}+\mu_{\mathrm{B}} W_{\mathrm{B}}} \\
& I_{\mathrm{Co}}=K_{\mathrm{Co}} C_{\mathrm{Co}} \frac{W_{\mathrm{Co}}}{\mu_{\mathrm{Fe}}^{\prime} W_{\mathrm{Fe}}+\mu_{\mathrm{Co}}^{\prime} W_{\mathrm{Co}}+\mu_{\mathrm{B}}^{\prime} W_{\mathrm{B}}} \\
& \frac{I_{\mathrm{Fe}}}{I_{\mathrm{Co}}}=\frac{K_{\mathrm{Fe}}}{K_{\mathrm{Co}}} \frac{C_{\mathrm{Fe}}}{C_{\mathrm{Co}}} \frac{W_{\mathrm{Fe}}}{W_{\mathrm{Co}}} \frac{\mu_{\mathrm{Fe}}^{\prime} W_{\mathrm{Fe}}+\mu_{\mathrm{Co}}^{\prime} W_{\mathrm{Co}}+\mu_{\mathrm{B}}^{\prime} W_{\mathrm{B}}}{\mu_{\mathrm{Fe}} W_{\mathrm{Fe}}+\mu_{\mathrm{Co}} W_{\mathrm{Co}}+\mu_{\mathrm{B}} W_{\mathrm{B}}} .
\end{aligned}
$$

In eqs. (7), (8) and (9): $\mu_{\mathrm{Fe}}=$ mass absorption coefficient for iron spectrum in relation to ironcontaining particles; $\mu_{\mathrm{Co}}=$ mass absorption coefficient for iron spectrum in relation to cobalt oxide particles; $\mu_{\mathbf{B}}=$ mass absorption coefficient of iron spectrum in relation to binder; $\mu^{\prime}=$ mass absorption coefficient of cobalt spectrum; $C_{\mathrm{Fe}}=$ iron content in ironcontaining particles; $C_{\mathrm{Co}}=$ cobalt content in cobalt oxide; $K=$ constant; and $W=$ particles mixing ratio by weight. The iron-cobalt spectrum intensity ratio is proportional to iron content if approximations $\mu_{\mathrm{Fe}} \approx \mu_{\mathrm{Fe}}^{\prime}, \mu_{\mathrm{Co}} \approx \mu_{\mathrm{Co}}^{\prime}$ and $\mu_{\mathrm{B}} \approx \mu_{\mathrm{B}}^{\prime}$ are obtained in eq. (9). Considering the effectiveness of the cobalt internal standard, the nonlinearity of the commercial samples was thought to be due to a slight difference between 


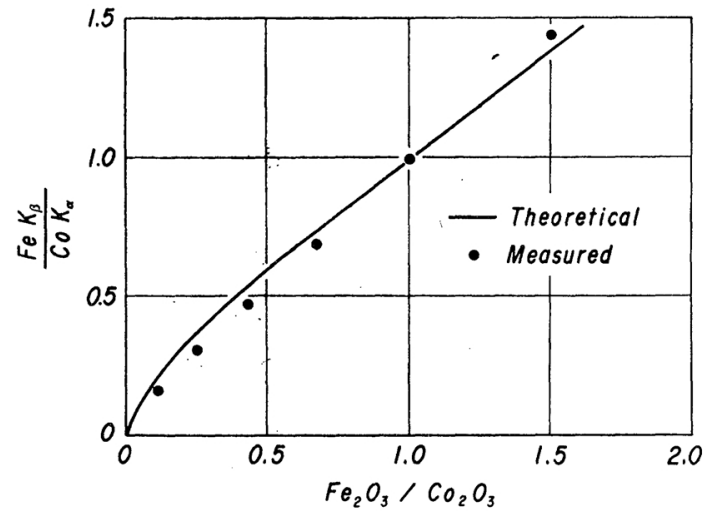

Fig. 10 Relation of $\mathrm{Fe} \mathrm{K} \beta / \mathrm{Co} \mathrm{K} \alpha$ vs $\mathrm{Fe}_{2} \mathrm{O}_{3} / \mathrm{Co}_{2} \mathrm{O}_{3}$ derived from dilution curve for $\mathrm{Fe}_{2} \mathrm{O}_{3}-\mathrm{Co}_{2} \mathrm{O}_{3}$ binary system.

the absorption coefficients for iron and cobalt spectra. Therefore, specimens were prepared by varying the mixing ratio of $\mathrm{Fe}_{2} \mathrm{O}_{3}$ and $\mathrm{Co}_{2} \mathrm{O}_{3}$ in the $\mathrm{Fe}_{2} \mathrm{O}_{3}-\mathrm{Co}_{2} \mathrm{O}_{3}$-binder combination. Figure 10 shows the analytical results obtained from these samples.

Again, no linear relationship was obtained with low iron content. This indicates that the effect of the internal standard differs with the relative contents of iron and cobalt in a specimen. Therefore, the internal standard method cannot simply be applied over a very wide $\mathrm{Fe}$ content range.

\section{Conclusion}

The effects of the internal standard on the particle size and mixing ratio, which are thought to be most influential on heterogeneous specimens, were studied. As a result the applicability of the internal standard method to mixed specimens was found to be limited. When compensating the iron spectrum in iron ore, the specimen particle size should be reduced to $2-3 \mu \mathrm{m}$ or finer. Of course, the particle size should be considered in relation to the extent of mixing. The internal standard is ineffective on the poorly mixed specimen. The specimens tested were prepared by the wet crushing method that assures better crushing and mixing. Consequently, the internal standard brought about good results. In other words, the specimens were homogenized to such an extent as permitted correction of matrix effects. This leads to more accurate analysis of pulverulent specimens.

\section{REFERENCES}

(1) M. Sugimoto: Bunseki Kagaku, 12 (1963), 475.

(2) M. Adachi and M. Ito: Denki Seiko, 37 (1966), 208.

(3) K. Hirokawa: J. Japan Inst. Metals, 24 (1960), 696.

(4) W. Marti: Spectrochim. Acta, 17 (1961), 379.

(5) H. J. Beattie and R. M. Brissey: Anal. Chem., 26 (1954), 980.

(6) F. Claisse and C. Samson. Advances in X-ray Analysis, Plenum Press, 5 (1961), p. 335.

(7) T. Reistad: Jernkont. Ann., 151 (1967), 216.

(8) Rompin (800), India (801), Texada (810), Dunzun iron ore (811), Philippine iron sand (830), Marcona pellets (850) and manganese ore (22a). (The Iron \& Steel Institute of Japan).

(9) Basic slag $(174 / 1,174 / 2)$, Liberian (175/1), Lincolnshire (301), Northsamptonshire iron ore (302), iron ore sinter (303) and manganese ore (176/1).

\section{Appendix}

\section{Deriving equation for the intensity of fluorescent X-rays from Claisse's mosaic specimen mixing model}

The intensity of fluorescent X-rays in the mixing model shown in Fig. 1 was derived as follows:

(i) When particles emitting the desired fluorescent X-rays are present at the surface:

(1) The fluorescent X-ray intensity $I_{p=0}^{f}$ from the particle layer $p=0$ is expressed as

$$
I_{p=0}^{f}=Q_{f} \rho_{f} C_{f} I_{0} \int_{0}^{a d} e^{-a_{f} x} \mathrm{~d} x=\frac{Q_{f} \rho_{f} C_{f} I_{0}}{a_{f}}\left(1-e^{-\alpha a_{f} d}\right) .
$$

(2) The fluorescent X-ray intensity $I_{p=1}^{f}$ from the particle layer $p=1$ is expressed as

$$
I_{p=1}^{f}=Q_{f} \rho_{f} C_{f} I_{0} e^{-\alpha a_{f} d} e^{-n a_{n} d} \int_{0}^{m d} e^{-a_{f} x} \mathrm{~d} x=\frac{Q_{f} \rho_{f} C_{f} I_{0}}{a_{f}} e^{-\alpha a_{f} d} e^{-n a_{n} d}\left(1-e^{-m a_{f} d}\right) .
$$


(3) The fluorescent X-ray intensity $I_{p=2}^{f}$ from the particle layer $p=2$ is expressed as

$$
\begin{aligned}
I_{p=2}^{f} & =Q_{f} \rho_{f} C_{f} I_{0} e^{-\alpha a_{f} d} e^{-n a_{n} d} e^{-\left(m a_{f}+n a_{n}\right) d} \int_{0}^{m d} e^{-a_{f} x} \mathrm{~d} x \\
& =\frac{Q_{f} \rho_{f} C_{f} I_{0}}{a_{f}} e^{-\alpha a_{f} d} e^{-n a_{n} d} e^{-\left(m a_{f}+n a_{n}\right) d}\left(1-e^{-m a_{f} d}\right)
\end{aligned}
$$

(4) Similarly, the fluorescent X-ray intensity $I_{p=p}^{f}$ from the particle layer $p=p$ is expressed as

$$
\begin{aligned}
I_{p=p}^{f} & =Q_{f} \rho_{f} C_{f} I_{0} e^{-\alpha a_{f} d} e^{-n a_{n} d} e^{-(p-1)\left(m a_{f}+n a_{n}\right) d} \int_{0}^{m d} e^{-a_{f} x} \mathrm{~d} x \\
& =\frac{Q_{f} \rho_{f} C_{f} I_{0}}{a_{f}} e^{-\alpha a_{f} d} e^{-n a_{n} d} e^{-(p-1)\left(m a_{f}+n a_{n}\right) d}\left(1-e^{-m a_{f} d}\right)
\end{aligned}
$$

Therefore, the fluorescent X-ray intensity $I_{f}$ for a specimen having particles emitting the desired fluorescent $\mathrm{X}$-rays at the surface is expressed as

$$
\begin{aligned}
I^{f}= & I_{p=0}^{f}+I_{p=1}^{f}+\cdots+I_{p=p}^{f}+\cdots=\frac{Q_{f} \rho_{f} C_{f} I_{0}}{a_{f}}\left[\left(1-e^{-\alpha a_{f} d}\right)+e^{-\alpha a_{f} d} e^{-n a_{n} d}\left(1-e^{-m a_{f} d}\right)+\cdots\right. \\
& \left.+e^{-\alpha a_{f} d} e^{-n a_{n} d} e^{-(p-1)\left(m a_{f}+n a_{n}\right) d}\left(1-e^{-m a_{f} d}\right)+\cdots\right]=\frac{Q_{f} \rho_{f} C_{f} I_{0}}{a_{f}}\left[1-e^{-\alpha a_{f} d}\left(1-e^{-n a_{n} d}\left(1-e^{-m a_{f} d}\right)\right.\right. \\
& \left.\left.\times\left\{\sum_{p=1}^{\infty} e^{-(p-1)\left(m a_{f}+n a_{n}\right) d}\right\}\right)\right]=\frac{Q_{f} \rho_{f} C_{f} I_{0}}{a_{f}}\left[1-e^{-\alpha a_{f} d} \frac{1-e^{-n a_{n} d}}{1-e^{-\left(m a_{f}+n a_{n}\right) d}}\right]
\end{aligned}
$$

(ii) When particles emitting the desired fluorescent X-rays are not present at the surface:

(1) The fluorescent X-ray intensity $I_{p=1}^{n}$ from the particle layer $p=1$ is expressed as

$$
I_{p=1}^{n}=Q_{f} \rho_{f} C_{f} I_{0} e^{-\beta a_{n} d} \int_{0}^{m d} e^{-a_{f} x} \mathrm{~d} x=\frac{Q_{f} \rho_{f} C_{f} I_{0}}{a_{f}} e^{-\beta a_{n} d}\left(1-e^{-m a_{f} d}\right) .
$$

is expressed as

(2) Similarly, the fluorescent X-ray intensity $I_{p=p}^{n}$ from the particle layer $p=p$

$$
I_{p=p}^{n}=Q_{f} \rho_{f} C_{f} I_{0} e^{-\beta a_{n} d} e^{-(p-1)\left(m a_{f}+n a_{n}\right) d} \int_{0}^{m d} e^{-a_{f} x} \mathrm{~d} x=\frac{Q_{f} \rho_{f} C_{f} I_{0}}{a_{f}} e^{-\beta a_{n} d} e^{-(p-1)\left(m a_{f}+n a_{n}\right) d}\left(1-e^{-m a_{f} d}\right) .
$$

Therefore, the fluorescent X-ray intensity $I_{n}$ for a specimen having no particles emitting the desired fluorescent X-ray at the surface is expressed as

$$
\begin{aligned}
I^{n}=I_{p=1}^{n}+I_{p=2}^{n}+\cdots+I_{p=p}^{n}+\cdots & =\frac{Q_{f} \rho_{f} C_{f} I_{0}}{a_{f}} e^{-\beta a_{n} d}\left(1-e^{-m a_{f} d}\right)\left\{\sum_{p=1}^{\infty} e^{-(p-1)\left(m a_{f}+n a_{n}\right) d}\right\} \\
& =\frac{Q_{f} \rho_{f} C_{f} I_{0}}{a_{f}} e^{-\beta a_{n} d} \frac{1-e^{-m a_{f} d}}{1-e^{-\left(m a_{f}+n a_{n}\right) d}} .
\end{aligned}
$$

From eqs. (14) and (17), the total fluorescent X-ray intensity, averaged over the thickness of the surface particle layers ( $\alpha d$ and $\beta d$ ), is expressed as follows:

$I=\left(\sum_{\alpha=1}^{m} I^{f}+\sum_{\beta=1}^{n} I^{n}\right) /(m+n)=\frac{Q_{f} \rho_{f} C_{f} I_{0}}{a_{f}} \frac{m}{m+n}\left[1+\frac{1}{m} \frac{e^{-a_{n} d}-e^{-a_{f} d}}{\left(1-e^{-a_{n} d}\right)\left(1-e^{-a_{f} d}\right)} \frac{\left(1-e^{-m a_{f} d}\right)\left(1-e^{-n a_{n} d}\right)}{1-e^{-\left(m a_{f}+n a_{n}\right) d}}\right.$. 